IN S T I T U T O

DE

M E D I C I N A

T R O P I C A L

DE

SÃO PAULO

JOURNAL OF THE SÃO PAULO INSTITUTE OF TROPICAL MEDICINE

1Universidade Federal do Piauí, Hospital Universitário, Teresina, Piauí, Brazil

${ }^{2}$ Hospital Getúlio Vargas, Teresina, Piauí, Brazil

${ }^{3}$ Universidade Federal do Piauí, Teresina, Piauí, Brazil

${ }^{4}$ Instituto de Doenças Tropicais Natan

Portella, Teresina, Piauí, Brazil

Correspondence to: Luis Gustavo

Cavalcante Reinaldo

Universidade Federal do Piauí, Hospital

Universitário, Campus I Campus

Universitário Ministro Petrônio Portela, SG

07 s/n, Ininga, CEP 64049-550, Teresina,

PI, Brazil

E-mail: Igreinaldo@yahoo.com.br

Received: 4 February 2020

Accepted: 22 April 2020
http://doi.org/10.1590/S1678-9946202062031

\section{Recurrent kala-azar: report of two cured cases after total splenectomy}

\author{
Luis Gustavo Cavalcante Reinaldo ${ }^{1,2}$, Raimundo José Cunha Araújo \\ Júnior ${ }^{1,2}$, Thiago Melo Diniz1, Rafael de Deus Moura', Dorcas Lamounier \\ Costa $^{3}$, Kelsen Dantas Eulálio ${ }^{4}$, Carlos Henrique Nery Costa ${ }^{3,4}$
}

\section{ABSTRACT}

In Latin America, the causative agent of kala-azar is the intracellular protozoan Leishmania infantum. Most cases in South America are reported in Brazil. Worldwide, it mainly affects Bangladesh, Ethiopia, India, South Sudan and Sudan. Despite the high morbidity and lethality of kala-azar, most infections are asymptomatic. However, a small portion of patients evolves with recurrence of kala-azar becoming symptomatic even after all available drug treatments. Kala-azar is not a formal indication for splenectomy in adults. Splenectomy is recommended as a saving measure, when kala-azar is associated with symptomatic hypersplenism and for drug-resistant cases. In the study, we report two cases of kala-azar with splenomegaly that presented several hospitalizations due to the recurrence of the kala-azar, in addition to hospitalizations for normalizing the blood count. After splenectomy, kala-azar cases and the effects of hypersplenism are cured. Thus, splenectomy should be seen as a surgical treatment option with a curative purpose in patients with recurrent kala-azar, in whom the possibilities of drug therapy have been exhausted and even so they progressed with hypersplenism and clinical repercussions.

KEYWORDS: Kala-azar. Splenectomy. Visceral leishmaniasis. Hypersplenism.

\section{INTRODUCTION}

In Latin America, the causative agent of kala-azar is the intracellular protozoan Leishmania infantum. Most cases in South America are reported in Brazil ${ }^{1}$. Worldwide, in addition to Brazil, kala-azar affects Bangladesh, Ethiopia, India, South Sudan and Sudan ${ }^{2}$. Leishmania infantum parasite multiply within the sand fly Lutzomyia longipalpis, during a period from 8 to $20 \mathrm{~d}$, and, in humans, has an incubation period between 2 and 6 months ${ }^{1}$. Despite the high morbidity and lethality of kala-azar, most infections by Leishmania infantum in humans are asymptomatic ${ }^{2}$. Individuals with low socioeconomic conditions and immune deficiencies are in general more susceptible and develop clinical signs ${ }^{3}$. Typical kala-azar manifestations include fever, weight loss, hepatomegaly, splenomegaly, and pancytopenia resulting from the replication of Leishmania amastigotes in macrophages, mainly in the liver, spleen, and bone marrow, causing serious injuries and ultimately death ${ }^{4}$. In the absence of treatment, death occurs within a few months after the onset of symptoms ${ }^{5}$. The treatment of immunocompetent patients is very efficient. It is composed of pentavalent antimonials that have been replaced by the liposomal amphotericin B or are associated with paramomycin or miltefosine, the latter for oral use ${ }^{6}$. Kala-azar is not a formal indication for splenectomy in adults, but splenectomyis recommended as a saving measure, when kala-azar is 
associated with symptomatic hypersplenism and in drugresistant cases $^{7-13}$

\section{CASE REPORTS}

\section{Case 1}

The male patient was born on June 26, 1986, in Paulistana municipality, Piaui State. He was hospitalized at the Natan Portella Institute of Tropical Diseases (IDTNP) on seven occasions between the years 2009 and 2011, with a consistent diagnosis of kala-azar confirmed by laboratory examination and tests including the finding of parasite amastigotes in bone marrow smears. The patient received all the recommended treatments, including the pentavalent antimony (glucantime, $20 \mathrm{mg}$ of $\mathrm{Sb}+5 \mathrm{~kg} / \mathrm{d}$ for $30 \mathrm{~d}$ in first hospitalization), liposomal amphotericin B (for $14 \mathrm{~d}$ at a dose of $3 \mathrm{mg} / \mathrm{kg} / \mathrm{d}$, in three subsequent hospitalizations) and pentamidine in the last hospitalization before surgery (4 mg/kg/d every other d, for a total of 15 doses), with only transient symptomatic improvement followed by recurrence. He had a negative HIV serological test. During the other two hospitalizations, the patient presented with anemia and was transfused twice with packed red blood cells. After the all the possibilities of treatment with medications were exhausted and the patient maintained a pancytopenia profile on the blood count due to hypersplenism, splenectomy was recommended. In January 2012, he was hospitalized for the surgical procedure. His clinical examination revealed mucocutaneous pallor $(2+/ 4+)$, fever $\left(38.5^{\circ} \mathrm{C}\right)$, dehydration $(2+/ 4+)$, distended abdomen with mild pain on deep palpation and splenomegaly $(8 \mathrm{~cm}$ below the left costal margin). Laboratory tests detected anemia, leukopenia, hypergammaglobulinemia and high levels of ESR (erythrocyte sedimentation rate) and CRP (C-reactive protein). On May 2, 2012 splenectomy was carried out and the patient was discharged $5 \mathrm{~d}$ after surgery. The first $24 \mathrm{~h}$ of the patient's postoperative period were held in the ICU (Intensive Care Unit) and due to bleeding during surgery, the patient received three packed red blood cell transfusions, evolving with stable hemoglobin and hematocrit values. The spleen measurements were $25 \times 17$ x $9 \mathrm{~cm}$, weighing $1860 \mathrm{~g}$. The histopathological study confirmed the presence of Leishmania parasites in the surgical specimen. The patient was referred to the IDTNP, where he underwent a new course of amphotericin B and was discharged on the $8^{\text {th }}$ day of hospitalization. He remained asymptomatic, with improvement observed in laboratory parameters no further relapse of leishmaniasis and has been followed-up at the outpatient clinic for more than seven years after the surgery. Unfortunately we have no images of this patient.

\section{Case 2}

The male patient was born on June 6, 1960, in Acaua municipality, Piaui State, was a married and was diagnosed with kala-azar in January 2014 and had a negative serology to HIV. Since then, he evolved with recurrent pancytopenia, persistent splenomegaly and a history of five previous hospitalizations at the IDTNP for the kala-azar treatment. After unsuccessful attempts with all the existing drug treatments against kala-azar, such as pentavalent antimony (glucantime, $20 \mathrm{mg}$ of $\mathrm{Sb}+5 \mathrm{~kg} / \mathrm{d}$ for $30 \mathrm{~d}$ at first hospitalization) and liposomal amphotericin B (for $14 \mathrm{~d}$ at a dose of $3 \mathrm{mg} / \mathrm{kg} / \mathrm{d}$, in three hospitalizations), and in the face of an evolution with hypersplenism, clinical and laboratory repercussions, the patient was admitted in July 2015 to undergo a splenectomy, and at that time, on the physical examination, he presented with a palpable spleen at $12 \mathrm{~cm}$ from the left costal margin. In the preoperative period, an ultrasound of the abdomen was performed showing an enlarged spleen extending to the left iliac fossa. CBC with Hb 8.7 g/dL; Ht 27.9\%; leukocytes 1,090/ $\mathrm{LL}$ and $155,000 / \mu \mathrm{L}$ platelets. He underwent splenectomy on August 04, 2015, progressing uneventfully in the intra and postoperative periods. The surgical specimen measured $19.5 \times 14.5 \times 6 \mathrm{~cm}$ and weighed 1,066g (Figures 1 and 2). The histopathological study confirmed the presence of Leihmania parasites within the splenic parenchyma. He also

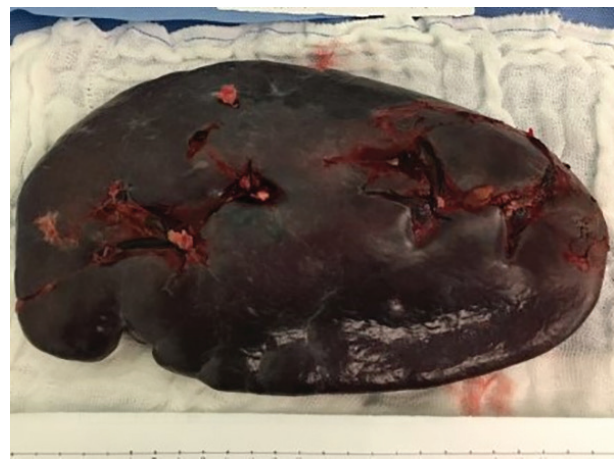

Figure 1 - Spleen: visceral surface (patient of the Case 2).

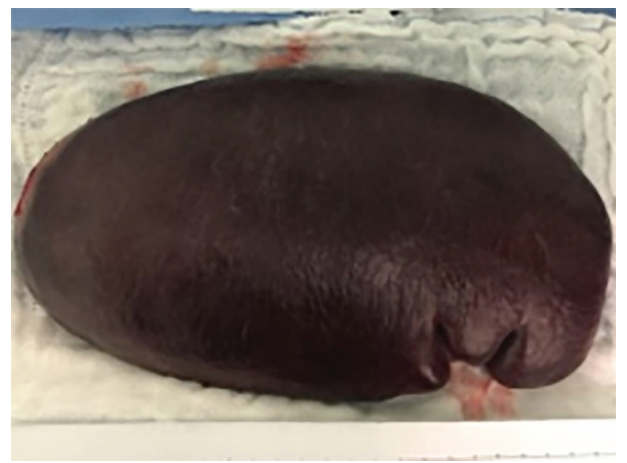

Figure 2 - Spleen: diaphragmatic surface (patient of the Case 2). 
had $7 \mathrm{~d}$ of liposomal amphotericin B during hospitalization. In the outpatient follow-up, cholelithiasis was identified, which became symptomatic and the patient underwent, a video cholecystectomy surgery on November 03,2017 , performed by the same team of the splenectomy, also evolving without complications. Nowadays, he has been followed-up at the outpatient clinic, for more than 4 years after the surgery, remaining asymptomatic, without further hospitalizations due to kala-azar or medications, and with a normal hematological profile.

\section{DISCUSSION}

The spleen behaves as a reservoir of Leishmania parasites in the human body and some studies have demonstrated a decreased action of anti-leishmania drugs on parasites ${ }^{10,14,15}$. It is part of the natural evolution of kala-azar to cause hypersplenism and consequent severe pancytopenia which, if left untreated, undoubtedly leads to death. The two studied patients, despite attempts of treatment with current drugs, evolved with recurrent kala-azar.

In order to define what is recurrent kala-azar, it is necessary to introduce two definitions: persistent kala-azar, when the patient has more than 6 months of signs and symptoms of the disease after the end of the initial specific treatment (liposomal amphotericin B for $14 \mathrm{~d}$ at a dose of $3 \mathrm{mg} / \mathrm{kg} / \mathrm{d}$, or an alternative medication) with the presence of parasites in the bone marrow; and relapsing kala-azar, when the patients who became asymptomatic, had recurrences 6 months after the initial diagnosis. Recurrent kala-azar occurs when the patients fall into persistent or recurrent kala-azar, or both. The patients in the study were classified as persistent and recurrent.

Splenectomy can be considered the treatment of choice for a number of hematological diseases, including idiopathic thrombocytopenic purpura, thrombotic thrombocytopenic purpura and hereditary spherocytosis ${ }^{11,12,16}$. There is also indication to perform splenectomy in patients with complications of the schistosomiasis infection in addition to trauma, splenic abscesses, neoplasia and in patients who do not respond to specific drug therapy for kala-azar-13. The latter was the indication for both reported patients. In all of these indications, with the exception of emergency surgeries, prior vaccination against encapsulated germs is necessary at least two weeks before the procedure ${ }^{17}$. This measure was adopted in the studied patients.

Many studies have shown that splenectomy, although not free of complications, is relatively safe: morbidity can reach $8 \%$ and long-term post-surgical mortality 4.5\%. Among the complications, hematomas, subphrenic abscesses, venous thromboembolism, pneumonia and fulminant sepsis after splenectomy, are the most cited ${ }^{18,19}$. In a study published in 2010, Thomsen et al. ${ }^{20}$ warned of an increased risk of developing thrombotic events (pulmonary thromboembolism and/or deep venous thrombosis) when compared to patients undergoing appendectomy and the general population. The first patient to be operated was younger, but had a larger spleen; remained during the first $24 \mathrm{~h}$ of the postoperative period in the ICU due to the intraoperative blood loss caused by technical difficulties. He received three packed red blood cell transfusions and was discharged from the ICU on the following day. The second patient, 55 years-old on the day of the surgery, evolved with no incidents in the trans and postoperative periods. Both patients remained asymptomatic, maintaining the kala-azar healed status, the first patient for over 7 years and the second one for 4 years.

\section{CONCLUSION}

Splenectomy should be seen as a surgical treatment option with a curative purpose for patients with recurrent kala-azar, in whom the possibilities of drug therapy have been exhausted and who develop hypersplenism with clinical repercussions.

\section{REFERENCES}

1. Laison R, Shaw JJ. Evolution, classification and geographical distribution. In: Peters W, Killick-Kendrick R, editors. The Leishmaniasis in biology and medicine. London: Academic Press;1987. p.1-20.

2. World Health Organization. Control of the leishmaniases: report of a meeting of the WHO Expert Committee on the Control of Leishmaniases, Geneva, 22-26 March 2010. Geneva: WHO; 2010. [cited 2020 Apr 23], Available from: https://www.who. int/neglected_diseases/resources/who_trs_949/en/

3. Pagliano P, Ascione T, Di Flumeri G, Boccia G, De Caro F. Visceral leishmaniasis in immunocompromised: diagnostic and therapeutic approach and evaluation of the recently released IDSA guidelines. Infez Med. 2016;24:265-71.

4. Brasil. Ministério da Saúde. Secretaria de Vigilância em Saúde. Departamento de Vigilância Epidemiológica. Manual de vigilância e controle da leishmaniose visceral. Brasília: Ministério da Saúde; 2014. [cited 2020 Apr 23], Available from: http://bvsms.saude.gov.br/bvs/publicacoes/manual_ vigilancia_controle_leishmaniose_visceral_1edicao.pdf

5. Marinkelle CJ. The control of leishmaniasis. Bull World Health Organ. 1980; 58:807-18.

6. Musa A, Khalil E, Hailu A, Olobo J, Balasegaram M, Omollo $\mathrm{R}$, et al. Sodium stibogluconate (SSG) \& paromomycin combination compared to SSG for visceral leishmaniasis in 
East Africa: a randomised controlled trial. PLoS Negl Trop Dis. 2012;6:e1674.

7. Rees PH, Kages PA, Kyambi JM, Ayim EN, Bhatt KM, Eeftinck JK. Splenectomy in kala-azar. Trop Geogr Med. 1984;36:28592.

8. Perez Bryan M. La esplenectomia en el kala-azar. Acta Pediatr Esp. 1949;7:1576-81.

9. Das A, Sen Gupta PC. Relapse of kala-azar after splenectomy. Lancet. 1950;2:681-2.

10. Lyngdoh E, Jain SC, Barua P. Splenectomy in treatment of drugresistant kala-azar. J Indian Med Association. 1971;57:458-61.

11. Assef JC, Favero SS, Szutan LA, Capua Júnior A. Recidiva hemorrágica em pacientes esquistossomóticos operados. Rev Col Bras Cir. 1998;25:265-70.

12. Ferraz AA, Lopes EP, Bacelar TS, Silveira MJ, Silva LM, Ferraz EM. Tratamento cirúrgico da hipertensão portal esquistossomótica no HC/UFPE: análise de 131 casos. Rev Col Bras Cir. 2000;27:332-7.

13. Dutra RA, Dutra LF, Reis MO, Lambert RC. Splenectomy in a patient with treatment-resistant visceral leishmaniasis: a case report. Rev Soc Bras Med Trop. 2012;45:130-1.

14. Berman J. Current treatment approaches to leishmaniasis. Curr Opin Infect Dis. 2003;16:397-401.
15. Troya J, Casquero A, Muniz G, Fernandez-Guerrero ML, Gorgolas M. The role of splenectomy in HIV-infected patients with relapsing visceral leishmaniasis. Parasitology. 2007;134:621-4.

16. Melo-Filho AA, Miranda ML, Oliveira-Filho AG, Pinheiro VG, Brandalise NA, Bustorff-Silva JM. Esplenectomia laparoscópica nas doenças hematológicas. Rev Col Bras Cir. 2003;30:382-7.

17. Marques RG, Petroianu A. Infecção fulminante pós-esplenectomia. Arq Gastroenterol. 2003;40:47-54.

18. Lozano-Salazar RR, Herrera MF, Vargas-Vorácková F, LópezKarpovitch X. Laparoscopic versus open splenectomy for imune thrombocytopenic purpura. Am J Surg. 1998;176:366-9.

19. Mazzucconi MG, Arista MC, Peraino M, Chistolini A, Felici C, Francavilla V, et al. Long-term follow-up of autoimmune thrombocytopenic purpura (ATP) patients submitted to splenectomy. Eur J Haematol. 1999;62:219-22.

20. Thomsen RW, Schoonen WM, Farkas DK, Riis A, Fryzek JP, Sorensen HT. Risk of venous thromboembolism in splenectomized patients compared with the general population and appendectomized patients: a 10-year nationwide cohort study. J Thromb Haemost. 2010;8:1413-6. 